\title{
Urban Sprawl: Scenario Analyses For Public Policy - Makers
}

John M. Polimeni, (E-mail: polimenj@acp.edu), Albany College of Pharmacy Raluca Iorgulescu Polimeni, (E-mail: rpolimeni@ siena.edu), Siena College

\begin{abstract}
This paper examines the likely effects of public-policy on residential development in the Wappinger Creek Watershed within Dutchess County in the Hudson River Valley of New York State. An econometric model is used in combination with Monte Carlo simulation to project residential development in a spatial format using a Geographic Information System (GIS). GIS was used to extract data with bio-geophysical attributes, such as slope, soil, and location characteristics, to project growth trends for residential use of undeveloped land parcels due to changes in public policy. Detailed scenarios present stakeholders the economic, social, and environmental implications of a possible course of action. The results indicate that public-policy can be effectively used to counteract the effects of urban sprawl and increased population.
\end{abstract}

\section{INTRODUCTION}

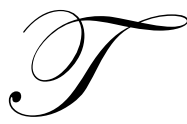

he research presented in this paper takes a unique approach to residential land-use modeling. Empirical studies on land-use have focused on the loss of forest or farmland, on explaining the urban fringe development process, or how land values or zoning have affected development. Few studies exist predicting the conversion of vacant land to residential use and where that conversion is likely to occur. The study presented in this paper uses economic variables to calculate land-use change on a residential level. Because economic changes drive land-use changes, and not the other way around, this method of calculation makes an important distinction.

Analysis of land-use change is complex because trends must be clarified and documented before the causes can be explained. However, as difficult as it may be, analyzing the economic and social processes in advance to determine land-use decisions is vital in order to make informed policy. By acquiring a clear understanding of the forces that alter the spatial landscape, policies may be designed that will lead to the desired changes in the development pattern of regions. The effectiveness of the policy recommendations depends on the accuracy of the scenarios based on land-use change models sensitive to local characteristics. The impact of policy options for mitigating the potential negative effects of land-use change is analyzed using scenarios that project residential development.

The study area for the research presented in this paper is the Wappinger Creek Watershed (210 sq-miles) in Dutchess County illustrated in Figure 1.

The Wappinger Creek Watershed is part of the larger Hudson River Watershed of eastern New York. Dutchess County (802 sq-miles) is midway between Albany, N.Y. and New York City. The Watershed contains ten towns and three villages, and drains approximately one-quarter of the county. The area is primarily agricultural and forestland in the north and becomes increasingly residential and commercial toward the southern tip, containing a clear development gradient that follows a southwest to northeast line.

Parcel size varies greatly depending on usage. Residential parcels average 3 acres, vacant parcels average 7.5 acres, agricultural parcels average 83 acres, and forest parcels average 55 acres in size. The majority of houses in the Watershed are moderate in size, averaging approximately 1750 square feet. Due to development pressure, housing 
of this size is being built throughout the Watershed. This development gradient provides a unique setting to model the social and bio-geophysical impacts on land-use.

The paper is organized as follows. Section 2 describes the theoretical and applied models of land-use. Section 3 describes the models and data used in this paper. Sections 4 and 5 present the results and analyses of the scenarios that were performed. The paper concludes with section 6 , a summary and discussion of policy implications.

\section{RESIDENTIAL LOCATION THEORY}

Understanding where residential development is likely to occur is important for municipalities trying to preserve their landscape and surrounding environment, but it is a complex task due to the difficulty of linking economic change to land-use change. The emphasis of residential location theory is on the relationship between housing location and values of other correlated economic factors, such as accessibility, land values, and development costs (Ricks, 1970). Traditional location and land use theory was founded by Johan Heinrich von Thünen (1966) and developed by Alonso (1964), Muth (1961, 1969, and 1985), and Mills (1972). These theories assume a monocentric structure where primary economic activity takes place, surrounded by concentric rings of development determined by economic constraints. These works have provided a basis for the more application-oriented research done recently.

McMillen (1989) used a multinomial logit model to predict land use in urban areas surrounding Chicago. Although McMillen's model was not constructed to predict land-use conversion, the findings do indicate that such a model is justifiable, as it identifies the current state of parcels accurately. McMillen and Singell (1992) found that an increase in residential distance from the central business district is proportional to the probabilities that a person works and lives in the suburbs. Extending the previous findings, Anas, Arnott, and Small (2000) found that equilibrium land rent, residential density, and consumption all decline exponentially with distance.

While these findings have dramatically increased the understanding of how and where residential developments are formed, further examination of the subject needs to be done to understand how the public policy affects residential development. This paper builds upon the findings described above. The next section describes the data and models used in this paper to examine different public policies that affect the spread of urban sprawl.

\section{DATA AND DESCRIPTION OF MODELS}

Location theory and its recent diligence to the phenomena of sprawl - as well as the public policy decisions that influence sprawl - lay the foundation for an application-based analysis of possible new residential locations under different public policy decisions. This section outlines the data and methodology used for a residential growth model of the Wappinger Creek Watershed of Dutchess County, New York.

\section{Data Description}

A combination of census block data and tax parcel data, obtained from the New York State GIS Clearinghouse and the Dutchess County Planning Department, was used to simulate residential development on vacant land parcels. The tax parcel data provides information such as assessment value, area in acres, age of unit, square footage of living space, and property class, as defined by the New York State Office of Real Property Services Assessors' Manual. Vacant land is that property which is not in use, is in temporary use, or lacks permanent improvement. Agricultural land is property that is used for the production of crops or livestock. Forestland, for this study, is private forestland property. The data also allow for an analysis of surrounding parcels so that an individual parcel can be given a probability weight for a particular pattern of development.

Census block data supplement tax parcel information and enables a complete socio-economic analysis of the county. Census blocks typically contain between 250 to 550 housing units, providing detailed household income, housing characteristics, and population growth data. All parcels, including vacant, take on the value of the socioeconomic variable for the census block in which they belong. 
Two separate income variables are considered: percentage change in per capita income and percentage change in median household income. Each of these variables is measured in real dollar terms from the 1990 to 2000 time period. The percentage change in per capita income variable indicates how income levels change for the overall population and are a key individual determinant in housing choices (Lombardini, 1996). Percentage change in median household income indicates how income levels change on a residential level. Household income is a key factor in determining the decline or the revitalization of neighborhoods (Downs, 1981). With the exception of percentage change in median household income in the Upper Watershed where the land is heavily agricultural, income varies very little throughout the Watershed.

Two population variables were considered: population density and percentage change in population growth. Population growth (number of people) increases the level of demand for residential parcels and for services (Heilbrun, 1974). However, the likely impact of increasing population density (population per square mile) is not clear. Low density could mean there is more room for growth, while high density could discourage new residential use. Alternatively, these impacts may be neighborhood effects that encourage new residential land-use in currently dense areas. Clearly, the more densely populated areas will have high residential land use, and the less densely populated areas will tend to be in agricultural and forestland areas. Population in the county is highly variable. Population density declines moving north in the Watershed from the lower gradient to the upper gradient, clearly illustrating three distinct regions. The opposite holds for percentage change in population, with the Upper Watershed growing at a faster rate than the Lower Watershed. The Lower Watershed had a negative growth rate for the past decade, indicating an exodus from urban areas to the suburbs and rural regions.

At the tax parcel level an important variable is assessed land value per acre (in 2000 dollars). The density of residential development varies directly with land values and with expected future demand (Ottensmann, 1977). Residential development is driven by lower land prices. Where land price is lower, people buy larger lots, increasing the amount of area needed for a given population (Heilbrun, 1974). Land values represent an index that summarizes the accessibility advantages of the parcel, relative to other parcels. These advantages include prestige, amenities, and quality of living (Chapin, Jr., 1965).

Another important variable determining residential location is distance to the central business district (in miles). This paper considers a central business district to be a retail or commercial center for a village, town, or city within Dutchess County. The importance of this variable is based on the need and/or desirability to reside within acceptable distances for employment, commerce, and entertainment. Typically the greater the distance to the central business district, the greater the elasticity of housing output (Muth, 1969).

The final independent variable is a neighborhood index, a unique variable created for the purposes of this study. The neighborhood index is equal to the total number of residential parcels in a census block divided by the sum total of residential and vacant parcels in that census block. The neighborhood index variable was created to illustrate landscape patterns within a certain radius, in this case a census block. A region that contains more residential parcels will have greater pressure for non-residential parcels to become residential.

\section{Description of Models}

The emphasis of this study is to identify the parcels most likely to be converted to residential use due to changes in public policy, such as development buffer zones around the river and zoning laws. Therefore, the parcels of most interest include vacant land, agricultural land, and private forest land. Agricultural and private forest parcels are included in the vacant property class because both property classes are prime candidates for development. All other property classes are assumed unchanged. This assumption implies that certain property classes (such as industrial) are considered irreversible in the short-run. Further, most of the parcels in the Watershed are either residential or vacant in class. Therefore, a binary logit model was chosen for this study to determine the likelihood that parcels in the Wappinger Creek Watershed will be converted to residential uses. A multinomial logit model was rejected because of the lack of variety in property classes and a lack of quantity of parcels in property classes other than residential. 
Four models with different combinations of independent variables were used to calculate the probabilities that a parcel will be converted to residential from existing vacant or agricultural parcels. A set of independent variables in a vector $X$ explains the response such that:

$Y_{i}^{*}=X_{i} \beta+\varepsilon_{i}$

where $\beta$ is a column vector of parameters to be estimated, $\varepsilon_{\mathrm{i}}$ is the stochastic error term, and $Y_{i}^{*}$ is the underlying latent continuous variable that indexes the property class of a vacant parcel so that:

$$
Y_{i}^{*}=\left\{\begin{array}{c}
1 \text { if } Y_{i}^{*} \text { vacant } \\
0 \text { if } Y_{i}^{*} \text { residential }
\end{array}\right.
$$

In this case, the probability that a parcel will be classified as vacant can be given by:

$$
P\left(Y_{i}^{*}=1\right)=\frac{e^{x_{i} \beta}}{1+e^{x_{i} \beta}}
$$

and the probability that a parcel will be classified as residential can be given by:

$$
P\left(Y_{i}^{*}=0\right)=\frac{1}{1+e^{x_{i} \beta}}
$$

Following Maddala (1993), the marginal effect of a particular independent variable, $X_{i}$, on the probability of the occurrence of the response is estimated by:

$$
\frac{\partial P(Y=1)}{\partial X_{i}}=\frac{e^{x_{i} \beta}}{\left[1+e^{x_{i} \beta}\right]^{2}} \beta_{k}
$$

The probabilities calculated from the binary logit regression are combined with digitized zoning data, as well as bio-geophysical data such as soils data information to form a grid that allows development only in those locations that are most likely to be developed. A Monte Carlo simulation was conducted to approximate the full range of possible outcomes of development by reproducing real-world variability. For example, while unlikely, a parcel obtaining a probability of $25 \%$ for residential development could be chosen for development with the simulation. In a real-world situation, this parcel might be developed even though the model predicts a low probability of development.

\section{RESULTS}

This section will present the results of the models used for analysis. Section 4.1 dicusses the results of the binary logit models that were used in this paper. Since the data and models used in this paper are spatial, error propagation analyses needed to be conducted to correct for any spatial autocorrelation that may be present. The results of these analyses are presented in Section 4.2.

\section{Binary Logit Results}

The results of four different specifications of the binary logit model using different combinations of the independent variables are presented in Table 1. 
For the four models, the signs on the coefficients are as anticipated, except for the positive coefficients on the population density variable. Population density could have a positive coefficient to indicate that people would choose to live in urban regions leaving currently vacant parcels vacant. The marginal effects confirmed the analysis of the signs on the coefficients of the independent variables.

Using Model 4 as an example, the empirical results suggest that the predicted probability that a parcel is vacant is, on average, by 0.0958 lower with a one-percent increase in per capita income. The other variables in Model 4 yield similar signs on the coefficients. The results indicate that residential land will be decentralized with increases in the magnitudes of the variables in Model 4, indicating land will be negatively affected. To determine the validity of the results, several goodness-of-fit results were used.

Limited dependent variable regression models do not have a universally accepted goodness-of-fit test. Therefore, two different tests are used in this paper, specifically the McFadden $\mathrm{R}^{2}$ and Estrella $\mathrm{R}^{2}$. As the goodnessof-fit tests indicate, the models predict well. Both the Estrella and McFadden tests have values over 0.20, an acceptable value for logit estimates (McMillan, 1989).

The next stage was to compare the results of the models to the real-world situation in the Wappinger Creek Watershed by simulating a distribution of all the parcels. The simulation serves as a calibration tool to ensure that build-out analyses will start on an accurate foundation. To make this comparison, a Monte Carlo simulation was used to calculate the total number of residential parcels predicted in the Watershed for each of the regression models. Random numbers evenly distributed between zero and one, were generated. If the random number was greater than the probability that a parcel will become residential, then the parcel was marked as a vacant parcel. However, if the random number was less than the probability that a parcel will be become residential, then the parcel was marked as residential. The results of the average of one hundred simulations are presented in Table 2.

With the exception of Model 1, the results indicate that the models are calibrated for the build-out scenario analyses.

\section{Error Propagation Analysis}

Some of the independent variables used in the models are correlated, suggesting spatial dependence exists. ${ }^{1}$ Therefore, further calibration of the models was necessary. Sensitivity analysis, where spatial data can be sensitized to error terms, was used to establish the variability in the outcome of the models given the occurrence of error (Fisher, 1991). Monte Carlo simulation was used to quantify the errors through stochastic simulation. The error propagation analysis was carried out using a normal probability distribution with the mean and variance for each variable in the model.

Model 4 was chosen as the model to be used for analysis of development probabilities and for the following scenario analyses performed because of its overall accuracy in predicting existing conditions within the Watershed. Using the mean and variance calculated by the binary logit model for each independent variable and the constant in the normal probability distribution, one-hundred simulations were run for each of the 23,531 parcels to account for the variation within the probability density function. Averaging the hundred results yields a mean and standard deviation for each parcel, clearly illustrating how sensitive development probabilities are to data error. Table 3 presents the results of the error propagation analysis for Model 4, which displays the number of parcels that deviate with the indicated percentage from the mean.

\footnotetext{
${ }^{1}$ Following LeSage (LeSage, 1997, 2000, LeSage and Smith, 2002), a spatial probit model was used to test for spatial dependence. The results in Appendix A1 indicate that spatial dependence was present, as indicated by the Rho coefficients. However, due to the use of different levels of geographic data, i.e. census block and parcel specific, the coefficients are unreliable.
} 
These results provide a complete range of development probabilities that the model can generate and clearly indicate that the results of the binary logit model are valid and robust because there is a very small variability, in percentage terms, from the mean.

As indicated by the results, the percent deviation from the mean is small for each of the variables. The constant, as expected, has the largest deviation with approximately $50 \%$ of the parcels having a deviation of two percent or greater. Percentage change in per capita income and the neighborhood index have the largest deviation from the mean. Only about one-third of the parcels for these variables have more than two percent deviation from the mean. There is much less deviation in the other variables in Model 4, as approximately $80 \%$ of the parcels have a one percent deviation from the mean or less. These results provide further evidence of the reliability of the model and scenario analyses of possible public policies can now be undertaken.

\section{SCENARIO ANALYSIS}

Scenario analysis is an essential tool for understanding the interaction and possible outcomes of planning processes and the relationship between socio-economic development and the environment. Analyses of future scenarios were performed to inform decision-makers of what public policies will influence the potential evolution of land-use in the Wappinger Creek Watershed. A full range of alternative scenarios allow for uncertainty associated with land-use planning to be managed. Ample sets of scenarios will describe the significant economic, social, and bio-geophysical aspects of future land use development.

A complete breakdown of the parcels in the Watershed had to be completed to classify land and account for environmental factors before any of the scenario analyses could be completed. The Wappinger Creek Watershed contains 23,531 parcels that are residential, vacant, agricultural, or private forestland. Of those parcels, 4,507 parcels are classified as either vacant, private forestland, or agricultural. Once the vacant parcels were segregated from the residential parcels, wetlands, hydric soils, and slopes of greater than $15 \%$ had to be subtracted from the parcels because development is not permitted in these areas. To accomplish this task, maps for wetlands, hydric soils, and $15 \%$ slopes were overlaid on the vacant parcels map in the geographic information system (GIS) to calculate the percentage overlap on vacant parcels. The percentage overlap was used to determine the amount of land in acres unfit for development for each parcel which was subtracted from each parcel to determine the acreage of total developable land.

Members of the Dutchess County Environmental Management Council suggested that $80 \%$ and $50 \%$ figures for land availability for development be used because roads and other development necessities will require some of the available land. The $50 \%$ land availability, while feasible, is highly unlikely due to the fact that developers will want to maximize the amount of land that can be used. Therefore, only the $80 \%$ land availability will be used for discussion in this paper.

After accounting for development needs, some parcels did not have any developable land. For example, after building roads and other infrastructure needs, a parcel in an area with a minimum lot size restriction of 1 acre may only have one-tenth of an acre to build residential structures on, thus not meeting the zoning requirement. The parcels that had land available for development were correlated with their zoning restrictions. Each plot's minimum lot size requirements were then divided into each of the available land percentages to determine the number of potential new houses that could be built on each parcel. For example, a 31 acre parcel with $8.23 \%$ of its land either classified as wetlands, $15 \%$ slopes, or hydric soils has approximately 28.85 acres that could be developed at the $100 \%$ available land for development. The 28.85 acres is multiplied by $80 \%$ to get 23.08 acres available for development. Now, assume that the parcel has a minimum lot size requirement of 5 acres. Under the $80 \%$ restriction, the number of potential new residences is five. In addition, we assume that parcels cannot be subdivided.

A probability of residential development for each parcel was calculated and then a Monte Carlo simulation, as described previously, was performed for each scenario. For each simulation, the number of parcels predicted for development and the number of potential homes on those parcels were calculated for each of the three available land 
restrictions. One hundred simulations were run for each of the scenarios, and the averages of the simulations were calculated. For each scenario, Model 4 and the $80 \%$ land availability were used unless otherwise noted.

The status quo growth scenario will serve as the base case for comparison against all other scenarios. The status quo scenario examined what would happen if Dutchess County experienced the growth of the 1990's with increases of 53\% in per capita income and $8 \%$ in population from 2000 to 2010 . This scenario predicts that on average 982 parcels will be residentially developed leading to an average of 8,833 new houses. An illustration of one simulation is in Figure 2. The numbers in parentheses in the map key indicate the number of parcels in that category. Clearly evident from Figure 2 is that most of the bigger parcels in the northern part of the Watershed will be developed and that residential development is uniformly distributed.

The results of a series of simulated scenarios categorized as either social or bio-geophysical, are presented in Table 4. Income related scenarios are not considered here because policy-makers have very little direct effect on income in Dutchess County, only an indirect effect. For example, policy-makers can help to attract new businesses to the region, but it is the new companies that effect income levels and these businesses are unlikely to pay more than market wages established in their locality. Furthermore, as stated previously, income is fairly uniform throughout the county. Therefore, the status quo condition for income and population are used in the scenarios that follow.

\section{Social Scenarios}

To test how policy decisions affect land use change, a series of societal changes were simulated, as described previously, to examine what the likely effects on residential development would be if policy-makers changed zoning laws throughout the Watershed. The zoning restrictions in these scenarios will be changed dramatically to illustrate the degree to which zoning affects residential development.

Two scenarios, illustrated in figures 3 and 4, examined what would happen if policy-makers decided that they wanted to contain growth only to the urban areas of the county. The first scenario examines a situation where the urban gradient had minimum lot size restrictions reduced to 0.01 acres and the other gradients, suburban and rural, had their minimum lot size restrictions increased to 10 acres. The 0.01 acre figure was chosen because it is the smallest minimum lot size requirement for any of the vacant parcels. Thus, new development is strongly encouraged to the urban areas. For example, a parcel in the suburban gradient with a development size of 2 acres would not be developed because the minimum lot size requirement was changed to 10 acres.

Under this case, an average of 785 parcels is marked for development creating a possible 25,056 new houses. The drastic increase in potential new residences is due to the decrease in lot size requirements, and in the same time effectively prohibiting some parcels from being developed in the suburban and rural areas. Furthermore, when development is encouraged in urban zones, downtown districts are more likely to be reinvigorated. These results suggest that a policy such as this would likely protect green-space in the county by reducing the amount of urban sprawl through larger lot sizes.

The second option examined what would happen if development was only allowed in the urban gradient (the southern-most region of the county) while keeping minimum lot size restrictions the same. Only an average of 231 parcels is predicted for development with a potential of 2,284 new houses. This policy would strongly diminish urban sprawl while allowing for new residential development to occur in the urban areas, protecting even larger sections of green-space than the previous scenario. In addition, under this scenario agricultural land would be protected completely and not face development pressure.

\section{Bio-Geophysical Scenarios}

Most of the bio-geophysical attributes are accounted for in the build-out analysis, but a few scenarios can be evaluated. One of the main assumptions of land-use studies is that agricultural land is a prime area for new residential development, but what would happen if residential development on agricultural parcels was banned? Due to the fact 
that this study involves watershed-scale development, another scenario will examine what would happen if residential development on parcels that are contiguous to the Wappinger Creek Watershed was banned.

\section{Agricultural Development}

First to be examined is the case of banning residential development of agricultural parcels. As performed by Polimeni (2005), a ban on development on agricultural parcels predicts that on average 838 parcels will be developed for a potential 5,483 new houses. This result should be expected as agricultural parcels in the Watershed tend to be large in size, thus capable of having many homes built on them. The findings indicate that given the opportunity, most agricultural parcels will be developed residentially and that the largest parcels, which tend to be agricultural and in the upper half of the Watershed, are most likely to be developed, as the status quo case demonstrates. An illustration of the results is in Figure 5 and can be compared to Figure 2 to see the dramatic decrease of approximately 24,320 acres that are preserved under a development ban.

\section{Riparian Development}

A scenario that prohibits residential development on parcels that contain some portion of the Wappinger Creek Watershed will be examined next. This scenario illustrates how Hudson River tributaries can be protected from harmful chemicals like pesticides and insecticides by means of a buffer-zone. Trees, grasslands, and other vegetation filter chemicals out of water before the water gets to the river system, thus preventing the river from being polluted. Under conditions that prohibited riparian development an average of 918 parcels are predicted for development creating, on average, a potential of 7,085 new houses. Comparing this result to the status quo growth scenario that permits riparian development, a vast difference in not only the number of parcels to be developed but also location can be seen in Figure 6.

Further examination shows a decrease of an average of 64 parcels predicted for development, translating into an average of 748 less new homes built. Other inferences can be made. First, riparian parcels will be developed, likely because people prefer waterfront property. Second, waterfront property is divided into medium to large sized parcels as indicated by the nearly 750 decrease in potential new houses. Should policy-makers decide that they want to protect Hudson River tributaries from harmful chemicals and provide a buffer-zone around the natural waters of the Watershed this scenario shows that they would be very effective in meeting their goal.

\section{Scenario Error Propagation Analysis}

The scenarios presented above yielded new regression results. Therefore, the reliability of each scenario had to be tested through error propagation analysis performed in the same manner as before. The means and variances for each variable of each scenario were used to create a normal probability distribution. One-hundred simulations were run for each of the parcels to take care of the variation within the probability density function. Averaging the hundred results provided a mean and standard deviation for each parcel, illustrating how sensitive the results of the scenario analyses are to data error. The results of the status quo scenario are presented in Table 5. Error propagation analyses for the bio-geophysical scenarios and the zoning scenarios did not have to be conducted because these scenarios are equivalent to the status quo condition. Other than the constant, the neighborhood index is the only variable that has a large number of parcels with a two percent or greater variation. However, as indicated by the results, all the variables have little deviation from the mean indicating that the scenario analyses provide valid results.

\section{CONCLUSIONS AND IMPLICATIONS}

Preserving open space is vitally important if stakeholders in a region want to protect their quality of life and economic viability. Dutchess County, located in the Hudson River Valley of New York State, is no exception. Protecting open space is an essential step in preserving the tributaries, landscape, rich soils, and wildlife in the county. The loss of open space is highly correlated to socio-economic change. Zoning laws are some of the key factors leading to a loss of open space and increased urban sprawl. Counties that use innovative preservation techniques tend to be more populous, affluent, and located in states with stronger environmental protection programs (Greenberg and 
Plopper, 1990). Therefore, finding a balance between socio-economic growth and the protection of open space has become a significant and complex issue in policy-making.

This paper has developed a framework for policy-makers to distinguish among the factors that influence the conversion of open space to residential use and those factors that can preserve open space. The model presented determined where new residential development will likely occur through the use of scenarios under certain social and bio-geophysical conditions. The empirical results from the model are robust, indicating that the use of a binary logit model is valid. Further, the results show a high level of predictability as two different goodness-of-fit tests indicate. The goodness-of-fit tests are further bolstered by the fact that the data are cross-sectional, which tend to lower such values. A Monte Carlo simulation was used to calculate the number of residential parcels predicted for development in the Watershed in order to calibrate the results of the models to real-world conditions. The means of the simulations yielded small deviations from actual data and supported the findings of the goodness-of-fit tests.

The empirical results are used in a series of social and bio-geophysical scenarios that indicate to policymakers what would be the likely consequences on open space for any possible initiatives designed to promote economic development. The scenario analyses indicated that the thrust of new residential development will likely occur in the upper watershed gradient which is primarily agricultural and forestland. The parcels in this part of the Watershed are larger lots that allow for developers to build many new houses on a single parcel. As expected, the middle part of the Watershed serves as a transitional area containing suburbs. The simulation results confirm the trend of decentralized development occurring across the landscape.

This paper illustrated how different public policies can affect residential development. With this information and models like the one in this paper, policy-makers can make informed decisions about how they would like to have residential development occur in their region.

\section{ACKNOWLEDGEMENTS}

The authors would like to thank John Gowdy and Elizabeth Polimeni for comments on previous versions of this paper.

\section{REFERENCES}

1. Alonso, W., 1964 Location and Land Use. Cambridge: Harvard University Press.

2. Anas, A, R.J. Arnott, and K.A. Small, 2000 The Panexponential Monocentric Model, Journal of Urban Economics 47 165-179.

3. Chapin, Jr., F.S., 1965, A Model for Simulating Residential Development, Journal of the American Institute of Planners $31120-125$.

4. Downs, A., 1981, Neighborhoods and Urban Development. Brookings Institution, Washington, D.C.

5. Fisher, P.F., 1991, "Modelling Soil Map-unit Inclusions by Monte Carlo Simulation," International Journal of Geographical Information Systems 5193 - 208.

6. Greenberg, M.R. and F.J. Plopper, 1990, Government Land Preservation and Communication Policies in Fast -growing Counties of the United States of America, Environment and Planning C: Government and Policy 8 $417-426$.

7. Henry, M.S., D.L. Barkley, and S. Bao, 1997, The Hinterland's Stake in Metropolitan Growth: Evidence From Selected Southern Regions, Journal of Regional Science 37479 - 501.

8. Heilbrun, J., 1974, Urban Economics and Public Policy. St. Martins Press, New York.

9. $\quad$ Kennedy, P., 1998, A Guide to Econometrics. Cambridge: The MIT Press.

10. Lombardini, S., 1996, Growth and Economic Development. Edward Elger, Cheltenham.

11. LeSage, J., 1997, Bayesian Estimation of Spatial Autoregressive Models, International Regional Science Review 20113 - 129.

12. 2000, Bayesian Estimation of Limited Dependent Variable Spatial Autoregressive Models, Geographical Analysis $3219-35$. 
13. LeSage, J., and T.E. Smith, 2002, A Bayesian Probit Model with Spatial Dependencies, Working Paper. http://www.econ.utoledo.edu/faculty/lesage/lesage.html

14. McMillen, D.P., 1989, An Empirical Model of Urban Fringe Land Use, Land Economics 65 138-145.

15. McMillen, D.P., and L.D. Singell, Jr., 1992, Work Location, Residence Location, and the Intraurban Wage Gradient, Journal of Urban Economics 32195 - 213.

16. Mills, E.S., 1972, Studies in the Structure of the Urban Economy. Baltimore: Johns Hopkins University Press.

17. Muth, R.F., 1961, Economic Change and Rural-Urban Land Conversions, Econometricia, XXIX 1-23.

18. 1969, Cities and Housing: The Spatial Pattern of urban Residential

19. $\quad$ Land Use. Chicago: University of Chicago Press.

20. 1985, Models of Land-Use, Housing, and Rent: An Evaluation, Journal of Regional Science 25 593-606.

21. Ottensmann, J.R., 1977, Urban Sprawl, Land Values and the Density of Development, Land Economics 53 389-400.

22. Polimeni, J.M., 2005, Simulating Agricultural Conversion to Residential Use in the Hudson River Valley: Scenario Analyses and Case Studies, Agriculture and Human Values 22 377-393.

23. Ricks, B., 1970, New Town Development and the Theory of Location, Land Economics 465 - 11.

24. von Thünen, J.H., 1966, The Isolated State. translated by Carla Wartenberg, Peter Hall (ed.), New York: Pergamon Press.

Figure 1

Map of Dutchess County illustrating the Wappinger Creek Watershed, the Hudson River and its tributaries, and the central business districts in the county outlined in the checkered region

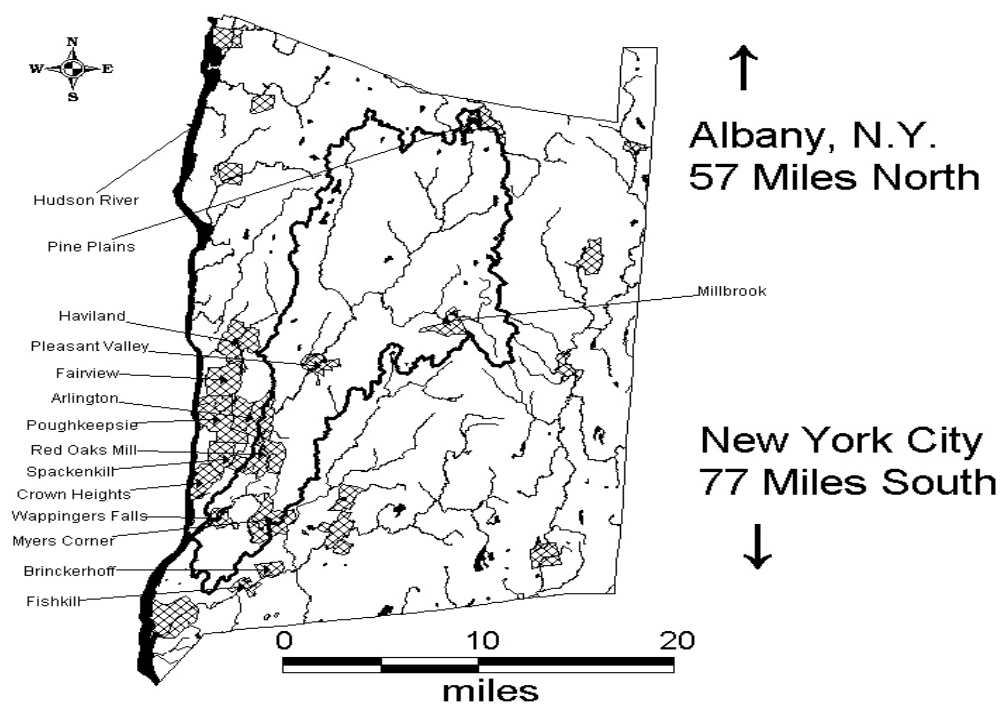


Figure 2

A simulation of residential development under the conditions of a $53 \%$ increase in per capita income and an $8 \%$ increase in population. Parcels predicted to be developed are in black.

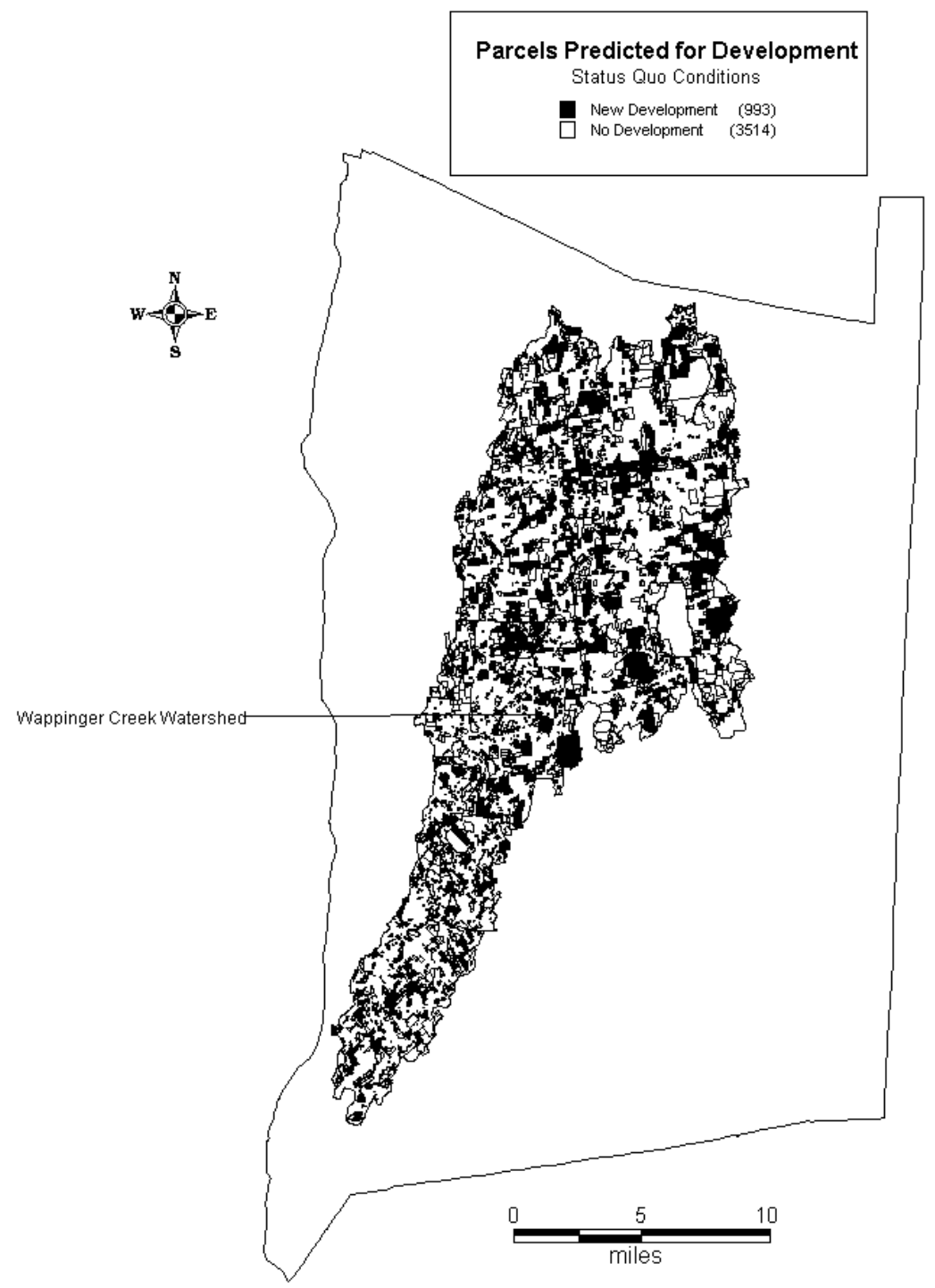


Figure 3

The urban gradient is given preference for residential development by decreasing the minimum lot size requirements to 0.01 acres and increasing the minimum lot size requirements in the other gradients to ten acres. The parcels predicted for development under this scenario are in black.

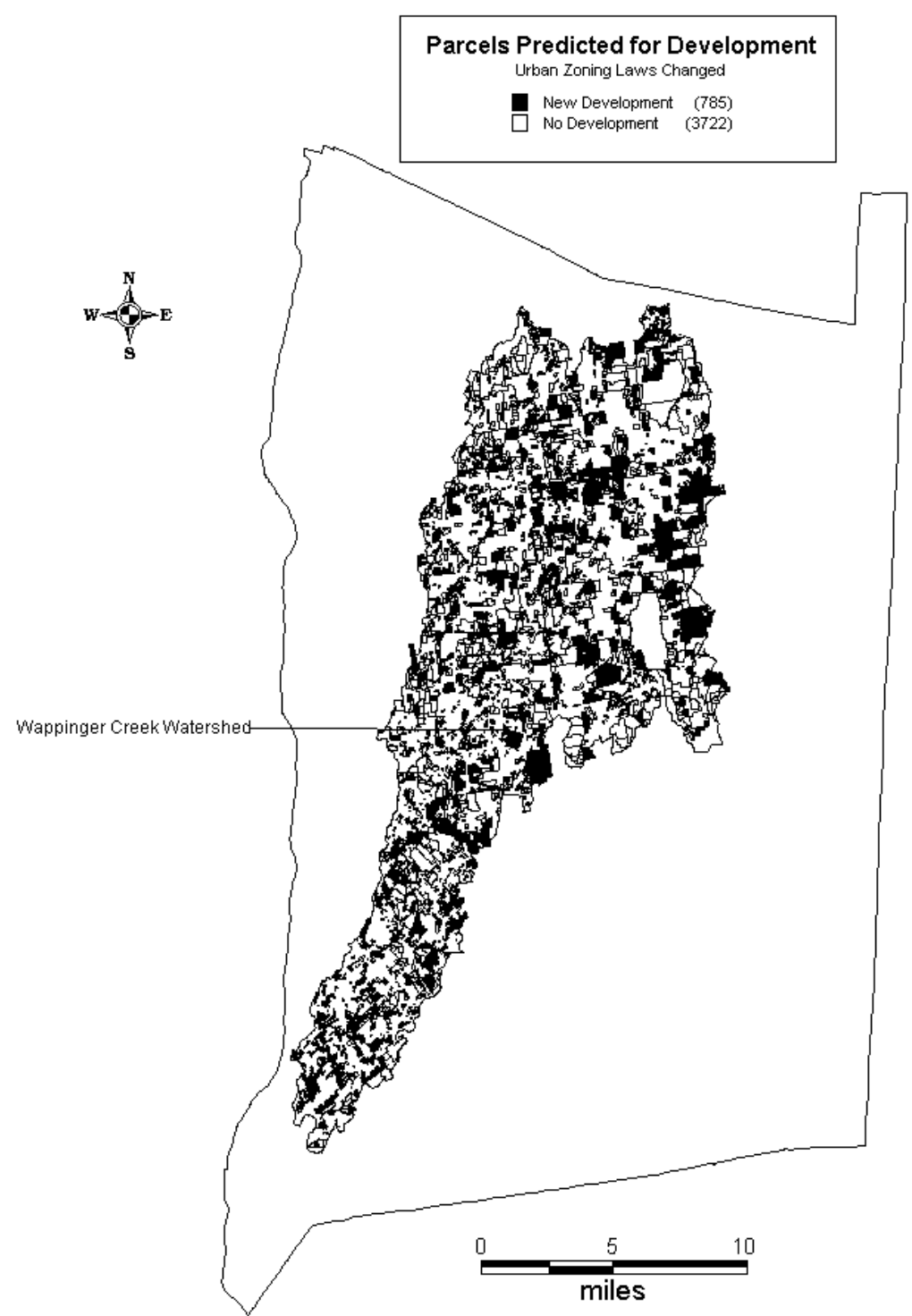


Figure 4

A simulation where residential development is allowed only in the urban gradient under current zoning laws

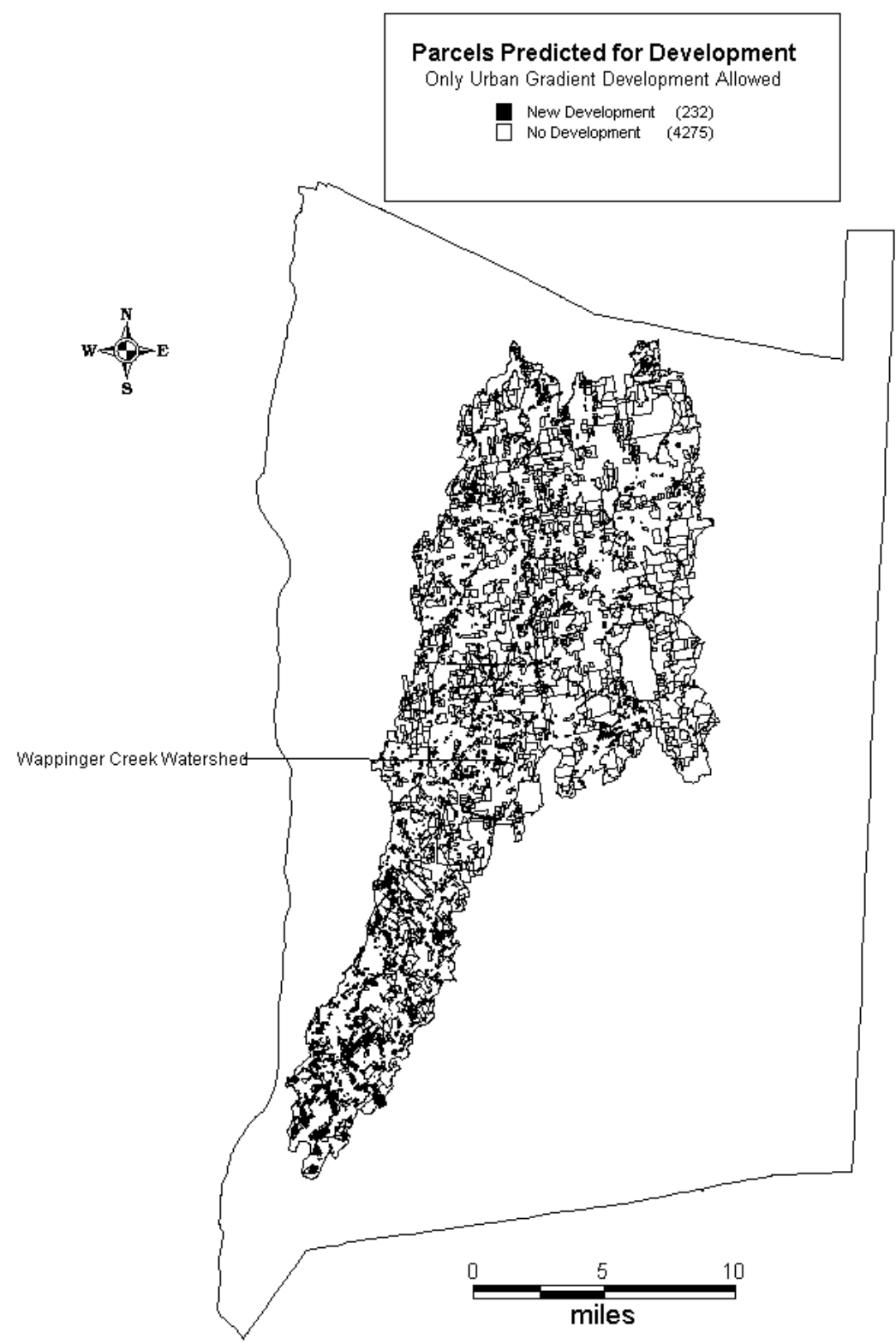


Figure 5

A simulation where agricultural parcels are prohibited from being residentially developed

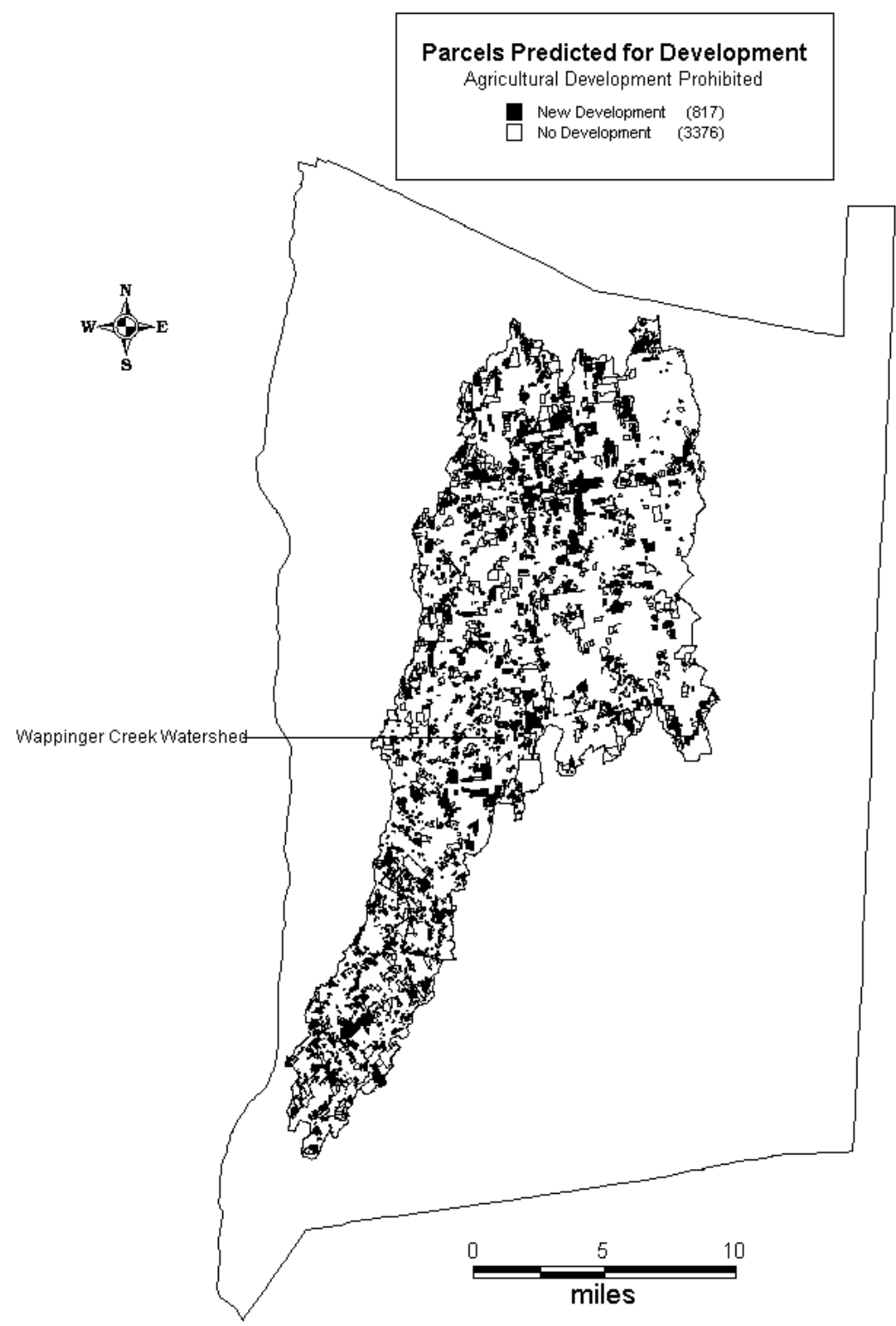


Figure 6

A simulation where parcels contiguous to part of the Watershed are prohibited from residential development




Table 1

Binary Logit Regression Results for the Entire Watershed

\begin{tabular}{|l|c|c|c|c|}
\hline \multicolumn{1}{|c|}{ Independent Variable } & Model 1 & Model 2 & Model 3 & Model 4 \\
\hline Constant & 4.0062 & 3.2568 & 4.095 & 3.551 \\
\hline \% Change in Per Capita Income (1990 - 2000) & $(24.38)$ & $(27.01)$ & $(22.84)$ & $(27.92)$ \\
\hline & -1.1191 & -- & -1.1087 & -- \\
\hline \% Change in Median Household Income (1990 - 2000) & $(-6.88)$ & -- & $(-5.99)$ & -- \\
\hline & {$[-0.0946]$} & -- & {$[-0.0958]$} & -- \\
\hline & -- & -0.3322 & -- & -1.2882 \\
\hline Population Density (People per Square Mile) & $--1.62)$ & -- & $(-5.85)$ \\
\hline & $5-69 \mathrm{E}-04$ & $5.11 \mathrm{E}-04$ & -- & {$[-0.1111]$} \\
\hline & $(16.49)$ & $(15.30)$ & -- & -- \\
\hline \% Change in Population (1990 - 2000) & {$[0.48 \mathrm{E}-04]$} & {$[0.437 \mathrm{E}-04]$} & -- & -- \\
\hline & -- & -- & -1.7363 & -1.8257 \\
\hline & -- & -- & $(-11.90)$ & $(-12.16)$ \\
\hline Current Land Assessment Per Acre (2000\$ per Acre) & -- & -- & {$[-0.14998]$} & {$[-0.15748]$} \\
\hline & $(-42.93)$ & $(-42.85)$ & $(-43.14)$ & $(-43.05)$ \\
\hline & {$[-0.41 \mathrm{E}-05]$} & {$[-0.41 \mathrm{E}-05]$} & {$[-0.4 \mathrm{E}-05]$} & {$[-0.4 \mathrm{E}-05]$} \\
\hline Distance to Central Business District (Miles) & -0.0962 & -0.09414 & -0.15939 & -0.16227 \\
\hline & $(-9.24)$ & $(-8.96)$ & $(-15.78)$ & $(-15.90)$ \\
\hline & {$[-0.0081]$} & {$[-0.0081]$} & {$[-0.01377]$} & {$[-0.013997]$} \\
\hline Neighborhood Index & -4.6038 & -4.3328 & -3.9793 & -3.8215 \\
\hline & $(-29.90)$ & $(-29.17)$ & $(-27.30)$ & $(-27.04)$ \\
\hline & {$[-0.3893]$} & {$[-0.3705]$} & {$[-0.3437]$} & {$[-0.3296]$} \\
\hline McFadden R ${ }^{2}$ & 0.2360 & 0.2339 & 0.2318 & 0.2314 \\
\hline Estrella R ${ }^{2}$ & 0.2354 & 0.2332 & 0.2311 & 0.2307 \\
\hline Note: & & $-4.77 \mathrm{E}-05$ & $-4.67 \mathrm{E}-05$ & $-4.66 \mathrm{E}-05$ \\
\hline
\end{tabular}

\section{Note:}

1) Z-statistics (logit uses $\mathrm{z}$ instead of $\mathrm{t}$ ) are reported (in parentheses) below coefficient estimates.

2) Marginal effects are reported [in brackets] below Z-statistics.

3) Significance tests at the $95 \%$ level.

4) Vacant parcels are those parcels coded as vacant plus agricultural parcels and private forestland parcels.

5) Vacant parcels are coded as a 1 in the dependent variable and residential parcels are coded as a 0.

6) Income variables are measured in 2000 dollars, population density is measured in people per square mile, current land assessment per acre is measured in 2000 dollars, and distance to central business district is measured in miles. 
Table 2

Monte Carlo Results and Statistics for Residential Parcels

\begin{tabular}{|l|c|}
\hline \multicolumn{1}{|c|}{ Models } & Residential Parcels in the Entire Watershed \\
\hline Initial Condition & 18,860 \\
\hline Model 1 & 18,860 \\
\hline Mean & 58.6295 \\
\hline Standard Deviation & $0.00 \%$ \\
\hline$\%$ Error from Initial Condition & 18,862 \\
\hline Model 2 & 46.6702 \\
\hline Mean & $0.01 \%$ \\
\hline Standard Deviation & 18,858 \\
\hline$\%$ Error from Initial Condition & 52.7775 \\
\hline Model 3 & $-0.01 \%$ \\
\hline Mean & \\
\hline Standard Deviation & 18,845 \\
\hline$\%$ Error from Initial Condition & 51.5848 \\
\hline Model 4 & $-0.08 \%$ \\
\hline Mean & \\
\hline Standard Deviation & \\
\hline$\%$ Error from Initial Condition & \\
\hline Note: & \\
\hline
\end{tabular}

Note:

1) Monte Carlo Predictions are the result of the average of 100 simulations for each gradient.

2) Separate Monte Carlo simulations were run for each gradient.

3) Percent error is the average amount of error for the three gradients and the entire watershed in absolute terms.

Table 3

Model 4 Error Propagation Analysis

\begin{tabular}{|l|c|c|c|c|c|}
\hline \multicolumn{1}{|c}{ Variable } & \multicolumn{5}{c|}{ Number of Parcels Deviating from the Mean } \\
\cline { 2 - 6 } & $\mathbf{0 \% - \mathbf { 0 . 5 \% }}$ & $\mathbf{0 . 5 \%} \mathbf{- 1 \%}$ & $\mathbf{1 \%} \mathbf{- 1 . 5 \%}$ & $\mathbf{1 . 5 \%} \mathbf{- 2 \%}$ & $\mathbf{2 \%}$ \\
\hline Constant & 5,331 & 3,084 & 1,598 & 1,314 & 12,204 \\
\hline Percentage Change in Per Capita Income & 7,961 & 2,951 & 2,315 & 2,544 & 7,760 \\
\hline Percentage Change in Population & 20,236 & 2,493 & 770 & 32 & 0 \\
\hline Current Land Assessment Per Acre (2000\$ per Acre) & 20,836 & 2,419 & 249 & 0 & 27 \\
\hline Distance to Central Business District (Miles) & 17,590 & 2,547 & 2,760 & 634 & 0 \\
\hline Neighborhood Index & 6,412 & 3,454 & 2,673 & 2,217 & 8,775 \\
\hline
\end{tabular}

Table 4

Scenario Analyses Results for Parcels Predicted for Development under the Assumptions of Per Capita Income (53\%) and Population Growth $(8 \%)$

\begin{tabular}{|c|c|c|c|c|c|c|}
\hline \multirow{2}{*}{ Scenario } & \multicolumn{3}{|c|}{ Percentage of Available Land } & \multicolumn{3}{|c|}{ Percentage of Available Land } \\
\hline & $100 \%$ & $80 \%$ & $50 \%$ & $100 \%$ & $\mathbf{8 0 \%}$ & $\mathbf{5 0 \%}$ \\
\hline \multicolumn{7}{|l|}{ Status Quo } \\
\hline Mean & 1,209 & 982 & 711 & & & \\
\hline Standard Deviation & 24.1354 & 21.5538 & 20.5562 & & & \\
\hline Social - Zoning & \multicolumn{3}{|c|}{ Contain Growth to the Urban Gradient } & \multicolumn{3}{|c|}{ Only Development in Urban Gradients Allowed } \\
\hline Mean & 972 & 789 & 681 & 284 & 231 & 160 \\
\hline Standard Deviation & 19.4101 & 16.8312 & 15.6792 & 7.1183 & 6.6410 & 5.9348 \\
\hline \multicolumn{7}{|l|}{ Bio-geophysical } \\
\hline 1. Agricultural & \multicolumn{3}{|c|}{ Agricultural Development Allowed } & \multicolumn{3}{|c|}{ No Agricultural Development } \\
\hline Mean & 1,209 & 982 & 711 & 1,062 & 838 & 579 \\
\hline Standard Deviation & 24.1354 & 21.5538 & 20.5562 & 20.21 & 17.09 & 14.75 \\
\hline 2. Riparian & \multicolumn{3}{|c|}{ Riparian Development Allowed } & \multicolumn{3}{|c|}{ No Riparian Development } \\
\hline Mean & 1,209 & 982 & 711 & 1,141 & 918 & 652 \\
\hline Standard Deviation & 24.1354 & 21.5538 & 20.5562 & 22.29 & 20.55 & 16.71 \\
\hline
\end{tabular}


Table 5

Error Propagation Analysis (Number of Parcels for the Status Quo Scenario)

\begin{tabular}{|l|c|c|c|c|c|}
\hline \multicolumn{2}{|c|}{ Variable } & \multicolumn{5}{c|}{ Standard Deviation } \\
\cline { 2 - 6 } & $\mathbf{0 \% - \mathbf { 0 . 5 \% }}$ & $\mathbf{0 . 5 \%} \mathbf{- 1 \%}$ & $\mathbf{1 \% - 1 . 5 \%}$ & $\mathbf{1 . 5 \%}-\mathbf{2 \%}$ & $\mathbf{2 \%}$ \\
\hline Constant & 4,545 & 2,658 & 1,898 & 1,101 & 13,329 \\
\hline Percentage Change in Per Capita Income & 9,454 & 3,704 & 5,770 & 4,505 & 98 \\
\hline Percentage Change in Population & 19,842 & 2,735 & 842 & 112 & 0 \\
\hline Current Land Assessment Per Acre (2000\$ per Acre) & 20,273 & 3,023 & 235 & 0 & 0 \\
\hline Distance to Central Business District (Miles) & 16,930 & 2,737 & 2,223 & 1,640 & 1 \\
\hline Neighborhood Index & 5,837 & 3,583 & 2,579 & 2,226 & 9,306 \\
\hline
\end{tabular}

Appendix A1

Spatial Binary Logit Regression Results

\begin{tabular}{|l|c|c|c|c|}
\hline \multicolumn{1}{|c|}{ Independent Variable } & Model 1 & Model 2 & Model 3 & Model 4 \\
\hline Rho & 0.535301 & 0.536649 & 0.536937 & 0.538168 \\
\hline Constant & 0.00 & 0.00 & 0.00 & 0.00 \\
\hline & -0.534916 & -0.53196 & -0.531561 & -0.529375 \\
\hline \% Change in Per Capita Income (\$) & 0.00 & 0.00 & 0.00 & 0.00 \\
\hline & -0.045017 & -- & -0.043986 & -- \\
\hline \% Change in Median Household Income (\$) & 0.00 & -- & 0.00 & -- \\
\hline & -- & -0.008997 & -- & -0.025767 \\
\hline Population Density (People per Square Mile) & -- & -- & 0.02 \\
\hline & 0.102701 & 0.2165 & -- & -- \\
\hline \% Change in Population & 0.00 & 0.00 & -- & -- \\
\hline & -- & -- & -0.047638 & -0.045888 \\
\hline Current Land Assessment Per Acre (2000\$ per Acre) & -0.344548 & -0.33256 & -0.323802 & -0.315219 \\
\hline & 0.00 & 0.00 & 0.00 & 0.00 \\
\hline Distance to Central Business District (Miles) & -0.256047 & -0.245913 & -0.075866 & -0.073203 \\
\hline & 0.00 & 0.00 & 0.00 & 0.00 \\
\hline Neighborhood Index & -0.045643 & -0.043783 & -0.242174 & -0.23378 \\
\hline & 0.00 & 0.00 & 0.00 & 0.00 \\
\hline Number of Observations & 23,531 & 23,531 & 23,531 & 23,531 \\
\hline
\end{tabular}

Note: p-values are reported below coefficient estimates. 